\title{
ROMEU E JULIETA NAS BANCAS DE REVISTA
}

Aline França Russo

Mestranda em Teoria da Literatura do Programa de Pós-Graduação em Estudos Literários /

UFMG

\section{RESUMO}

Romeu e Julieta é a história de amor mais conhecida do mundo. O chamado “romance rosa” recebeu alguma influência dessa obra? Este artigo procura responder a essa questão por meio de uma comparação da versão em prosa da peça, escrita pelos irmãos Lamb em 1807, com os romances de M. Delly, vendidos em bancas de revistas brasileiras nas décadas de 1930 a 1960.

\section{PALAVRAS-CHAVE}

Romeu e Julieta, M. Delly, romance

\section{INTRODUÇÃO}

Romeu e Julieta é uma peça teatral trágica escrita por Shakespeare entre 1591 e 1595 que conta a história de um casal de adolescentes de famílias rivais de Verona que vivem um amor proibido. Ainda na época de Shakespeare e atualmente é uma das mais conhecidas do bardo.

Cada peça de Shakespeare possui um tema diferente e muitas delas se tornaram o modelo de algum tipo de experiência humana. Indiscutivelmente, Romeu e Julieta é considerado o protótipo do amor apaixonado juvenil. Atualmente, a maioria das pessoas não tiveram acesso ao texto original da peça; entretanto, por meio das muitas adaptações e apropriações do texto em histórias em quadrinhos, filmes, desenhos animados, novelas, crônicas e na fala do cotidiano, quase todo mundo sabe o mínimo necessário sobre o enredo e compreende quando alguém chama um casal apaixonado de "Romeu e Julieta”.

Se considerarmos que Romeu e Julieta é a história de amor mais conhecida do mundo e sobre a qual já se foram feitas mais paródias, adaptações, apropriações, etc., é de se esperar 
que a literatura, vulgarmente chamada "romance rosa” ou “romance água com açúcar”, tenha recebido alguma influência dessa peça tão canônica. Para verificar essa influência, utilizei, na comparação, a versão em prosa da peça, escrita pelos irmãos Charles e Mary Lamb em 1807, uma vez que se é mais fácil analisar dois textos escritos em prosa, e a adaptação dos irmãos Lamb é bastante conhecida e fiel ao texto de Shakespeare. Pode-se dizer que, no geral, as pessoas ficam conhecendo a história de Romeu e Julieta mais através dessa adaptação, muito comum de ser lida ainda na infância, do que tendo acesso ao texto original.

Serão objetivos deste artigo verificar de que maneira encontramos semelhanças e diferenças entre:

- as características do casal protagonista dos romances de banca e o casal Romeu e Julieta;

- o enredo dos livros de banca e o da história Romeu e Julieta.

Para chegar à conclusão desses dois aspectos, dividiremos o artigo em algumas partes que cumprirão o objetivo de:

- explicar por que não podemos considerar Shakespeare como o de um só autor nem suas peças como originais;

- explicar como continuamos encontrando ressonâncias da obra de Shakespeare na produção cultural atual;

- explicar o que são os livros de banca;

- comparar cinco livros de banca com a história de Romeu e Julieta, apontando as semelhanças e diferenças.

\section{SHAKESPEARE, O MITO}

Como várias peças do autor, Romeu e Julieta não foi uma criação original. As premissas básicas de seu enredo já eram conhecidas, uma vez que é baseada em um antigo conto italiano que foi traduzido em forma de versos como “A trágica história de Romeu e Julieta” por Arthur Brooke em 1562 e também escrito em prosa com o título de Palácio do prazer por Willian Painter em 1582. A peça é bastante parecida com ambos os textos de Brooke e Painter, mas Shakespeare expandiu o enredo, dando mais espaço para os personagens coadjuvantes Páris e Mercúcio. A obra foi publicada, inicialmente, em 1597; uma versão tida como inferior às posteriores que ganharam em qualidade. 
Como bem disse Terence Hawkers, ${ }^{1}$ na "Introdução” de Alternative Shakespeare 2, foram criados vários mitos a respeito de Shakespeare, sendo alguns deles: 1) Shakespeare é um sábio, um gênio possuidor de uma capacidade incrível de revelar a psicologia humana; 2) suas peças apresentam uma amostra dos tipos humanos, exemplificando suas características boas e ruins; 3) seu trabalho é válido universalmente para todos os seres humanos em todas as épocas; entre outros.

A respeito da genialidade de Shakespeare, devemos ressaltar que muitas de suas peças foram baseadas em contos populares e tradicionais e que a crítica literária já provou que Shakespeare não era o único autor de suas peças. Realmente, se um único homem houvesse criado sozinho todas as peças que são atribuídas a Shakespeare, ele seria um grande gênio; entretanto, não foi isso que ocorreu.

Em relação aos personagens de Shakespeare representarem tipos humanos “universais”, é importante contrapor que não podemos afirmar que a natureza humana é permanente ou sequer que exista uma "natureza humana” indivisível e igual para todas as culturas, crenças e raças. Provavelmente haverá alguma cultura no mundo que não se verá representada pelos personagens de Shakespeare.

Finalmente, sobre a época, devemos questionar se a passagem do tempo histórico não abalará de algum modo a recepção das peças de Shakespeare.

Ainda com todas essas ressalvas, podemos dizer que Shakespeare - tomando esse nome como o autor ou os autores das peças - foi o responsável por tornar as histórias que escreveu - sejam elas conhecidas anteriormente ou não - documentadas, sobreviventes ao tempo, populares, famosas e mundialmente conhecidas. Se Shakespeare não foi um grande gênio, pelo menos foi um homem que soube captar e reunir, com ajuda de outras pessoas, muito da energia, cultura e tradição que circulavam em sua época.

\section{RESSONÂNCIAS DOS TEXTOS DE SHAKESPEARE NA CULTURA ATUAL}

Marjorie Garber, na "Introdução” de seu livro Shakespeare and modern culture, explica como "Shakespeare cria a cultura moderna e a cultura moderna cria Shakespeare”. 2 Portanto, nesta seção, basearei a explicação e meus comentários a partir da “Introdução” dessa obra.

\footnotetext{
${ }^{1}$ HAWKERS. Introduction.

${ }^{2}$ GARBER. Introduction, p. xiii. Todos os trechos em inglês foram traduzidos por mim, exceto o excerto da obra de Jane Austen, que foi traduzido por Rachel de Queiroz.
} 


\section{Garber afirma que}

Shakespeare deu o roteiro de muitas das idéias que nós consideramos "naturalmente" nossas e mesmo "naturalmente" verdadeiras; idéias sobre o caráter humano, a individualidade e o eu, sobre o governo, sobre homens e mulheres, juventude e velhice, sobre as qualidades que compõem um líder forte. $^{3}$

Além das ideias contidas no enredo, personagens como Romeu, Hamlet, Lady Macbeth tornaram-se tipos instantaneamente reconhecíveis quando seus nomes são evocados. As versões modernas desses personagens não precisam ser necessariamente idênticas ao personagem; Romeu, por exemplo, é o amante persistente em vez de um amante destinado à morte; Hamlet é um indeciso; e Lady Macbeth é, para a imprensa, uma mulher ambiciosa na política.

Atualmente, o termo “'shakespeariano” é considerado um adjetivo de uso geral, que significa 'grande’, ‘trágico’ ou 'vibrante’: é aplicado a eventos, pessoas e emoções, quer tenham alguma relevância real em relação a Shakespeare, quer não.”4

Terence Hawkers, na "Introdução" de Alternative Shakespeare, recorda que Shakespeare "aparece mundialmente em camisetas, selos de correio e cartões de crédito, bem como no título de monografias acadêmicas e teses de doutorado"; 5 seu nome é tão familiar em bares e restaurantes quanto em salas de aula e em palestras.

Jane Austen colocou na fala de Henry Crawford, um dos personagens de Mansfield Park: ${ }^{6}$

Mas a gente fica conhecendo Shakespeare não se sabe como. É uma parte da constituição inglesa. Seus pensamentos e encantos estão tão espalhados por todo o mundo que o encontramos em toda a parte; fica-se íntimo dele por instinto. Nenhum homem de alguma inteligência é capaz de abrir uma boa parte de uma de suas peças sem lhe cair imediatamente no fluxo dos

\footnotetext{
3 "Shakespeare has scripted many of the ideas that we think of as 'naturally' our own and even as 'naturally' true; ideas about human character, about individuality and selfhood, about government, about men and women, youth and age, about qualities that make a strong leader" (GARBER. Introduction, p. xiii)

4 "Shakespearean is now an all-purpose adjective, meaning great, tragic, or resonant: it's applied to events, people, and emotions, whether or not they have any real relevance to Shakespeare" (GARBER. Introduction, p. Xiv).

5 "appears world-wide on T-shirts, postage stamps and credit cards as well as in the titles of learned monographs and Ph. D. dissertations” (GARBER. Introduction, p. 1).

${ }^{6}$ Disponível em: <http://pt.scribd.com/doc/26081336/MANSFIELD-PARK-Portugues>. Acesso em: maio 2012.
} 
pensamentos. $^{7}$

A essa fala, seu interlocutor responde:

Não há dúvida de que Shakespeare nos é familiar até certo ponto, disse Edmund, desde a primeira infância. As passagens célebres são repetidas por todo o mundo; estão na maior parte dos livros que lemos, e nós todos falamos com Shakespeare; usamos suas imagens; descrevemos com as suas descrições $^{8}$

Marjorie Garber lembra também que Ralph Waldo Emerson, em 1850, disse que "hoje a literatura, a filosofia e o pensamento estão 'shakespearizados'. Sua mente é o horizonte além do qual, atualmente, não vemos. Nossos ouvidos estão educados para a música pelo seu ritmo."9

Dessa forma, fica claro que Shakespeare está completamente disseminado em nossa cultura. "Shakespeare sampleado, Shakespeare citado sem aspas, tornou-se uma língua franca

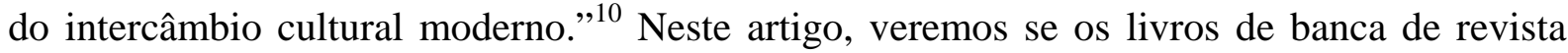
contêm em seu enredo ou na caracterização de seus personagens algo de Shakespeare ou shakespeareano.

\section{OS ROMANCES DE BANCA: APRESENTAÇÃO}

As bancas de revistas sempre venderam livros no Brasil. Entretanto, é de conhecimento geral que os títulos vendidos nas bancas não são os mesmos vendidos em livrarias. Na maioria das vezes, são comercializados obras de autores pouco conhecidos, vendidos em encadernações baratas, feitas de papel jornal. Atualmente esses livros são

\footnotetext{
7 "Shakespeare one gets acquainted with without knowing how. It is part of a British man's constitution. His thoughts and beauties are so spread abroad that one touches them everywhere, one is intimate with him by instinct. - No man of any brain can open at a good part of one of his plays, without falling into the flow of his meaning immediately" (AUSTEN. Mansfield Park, capítulo 34 da versão digital disponível em: <http://classiclit.about.com/library/bl-etexts/jausten/bl-jaustenman-34.htm>).

8 "No doubt one is familiar with Shakespeare in a degree, said Edmund, from one's earliest years. His celebrated passages are quoted by everybody; they are in half the books we open, and we all talk Shakespeare, use his similes, and describe with his descriptions" (Disponível em: $<$ http://classiclit.about.com/library/bl-etexts/jausten/bl-jausten-man-34.htm>).

9"Now, literature, philosophy, and thought, are Shakespearized. His mind is the horizon beyond which, at present, we do not see. Our ears are educated to music by his rhythm” (GARBER. Introduction, p. xviii).

10 "Shakespeare sampled, Shakespeare quoted without quotation marks, has become a lingua franca of modern cultural exchange” (GARBER. Introduction, p. xviii).
} 
considerados por muitas pessoas como "literatura inferior", por conterem quase sempre a mesma história, uma receita ou forma que contêm aristocratas e plebeus que se apaixonam, não podem ficar juntos, têm relacionamentos sexuais descritos de forma intensa e, após muitas complicações e sofrimentos, conseguem a sonhada união.

Todavia, nem sempre esses livros foram considerados inferiores. De 1935 a 1960, a Companhia Editora Nacional, de São Paulo, publicou três coleções de livros “para moças”, as chamadas Coleção Azul, Coleção Rosa e Coleção Verde. Todas incluíam apenas histórias de amor dirigidas a um público feminino. Das três, a mais popular foi a Coleção Verde, também chamada de "Biblioteca das Moças”, que contava com 175 títulos, sendo M. Delly (pseudônimo literário de um casal de irmãos franceses) “o autor” mais popular, com 29 títulos, seguido de Elinor Glyn, Bertha Ruck, Concordia Merrel e Guy de Chantepleure.

Segundo Maria Teresa Santos Cunha, ${ }^{11}$ as obras de M. Delly chegaram ainda mais cedo ao Brasil, ainda na década de 1920, importadas de Portugal, onde eram publicadas na coleção "Biblioteca das famílias”. Tanto na Europa quanto no Brasil, os livros eram aprovados pela Igreja Católica e tinham a sua leitura incentivada pela escola, sendo lidas, principalmente, entre jovens normalistas. Em edições baratas, vendidas em livrarias e em bancas de jornal, alguns títulos de M. Delly alcançaram várias edições. Dentre estas, destacam-se, Magali (10 edições), Mitsi (oito edições) e Freirinha (seis edições). "Uma edição comportava, em média, 3.000 a 4.000 exemplares.” Em 1983, os romances açucarados de M. Delly voltaram a ser editados pela mesma Companhia Editora Nacional. Entretanto, segundo Cunha, 12 “as vendas ficaram aquém do esperado”.

Os irmãos franceses Frédéric Henri Petitjean de la Rosiére (Vannes, 1870; Versailles, 1949) e Jeanne Marie Henriette Petitjean de la Rosiére (Avignon, 1875; Versailles, 1947) eram católicos fervorosos e críticos das novidades do seu tempo, preferindo as tradições e o modo de viver do século 19. Por isso, é fácil enxergar em seus livros a intenção de “educar” a leitora quando a protagonista é descrita, que, de acordo com as pesquisas Rosane Prado ${ }^{13}$ e de Cunha, ${ }^{14}$ fisicamente, como portadora de "pele nacarada”, “tez aveludada”, “andar gracioso”, “voz de timbre cálido”, “dedinhos afilados”, “cabelos sedosos e macios”, “flava cabeleira” e, moralmente, apresentada como “virtuosa”, “santa criatura”, “piedosa alma”, “caráter reto”,

\footnotetext{
${ }^{11}$ CUNHA. Armadilhas da sedução: os romances de M. Delly.

${ }^{12}$ CUNHA. Armadilhas da sedução: os romances de M. Delly, p. 41.

${ }^{13}$ PRADO. Um ideal de mulher: estudo dos romances de M. Delly.

${ }^{14}$ CUNHA. Armadilhas da sedução: os romances de M. Delly.
} 
“plena de candura”, “discreta”, “sofredora”, cheia de "graça natural” e de “profundo encanto”. As heroínas são modelos de virtudes, de alma ardente, religiosas, dispostas à caridade e às atividades do lar. Muito pudicas, ruborizavam e desfaleciam com frequência. Sua beleza inocente e cândida, a pureza de seu caráter e a firmeza de suas convicções e princípios morais encantavam o herói. Não raro, alguma característica negativa do herói, como a arrogância, o excesso de orgulho aristocrático, a vaidade, a falta de fé religiosa ou o autoritarismo eram superados devido ao amor.

A condição de aristocrata deixava de ser importante, especialmente no caso de a heroína não ter sangue azul, para dar-se maior relevância aos valores morais, que vinham de berço, uma vez que a maioria dos romances apresenta os protagonistas ainda na infância e adolescência.

Embora em algumas obras o casal se una em matrimônio desde o início da história e tenha filhos, jamais é feita nenhuma alusão a um contato físico mais intenso. Nem mesmo o quarto do casal é descrito, muito menos a noite de núpcias. Raramente se pode ler sobre um beijo trocado entre o par romântico. Na maioria das vezes, tudo não passa de um "roçar de lábios”. Apenas uma das heroínas de M. Delly tinha uma profissão, que abandonou quando se casou. As demais geralmente moravam em um palácio ou mansão, sob a tutela de um homem após a morte dos pais, sendo que muitas vezes acabavam por se apaixonar, entre os 16 e os 22 anos, pelo próprio tutor, um homem sete a 15 anos mais velho, dotado de um físico vigoroso, de orgulho e altivez e de um caráter reto e honrado, algumas vezes excessivamente autoritário ou indiferente, o que causava sofrimentos à heroína.

Atualmente são outros os livros vendidos nas bancas. Parecendo dar continuidade aos romances da coleção Biblioteca das Moças, com inúmeros aspectos similares, mas com nova roupagem, mais adequada ao século 21, surgiram, em 1977, as coleções Sabrina, Júlia e Bianca, da Editora Nova Cultural, de São Paulo, também vendidas em bancas de jornais. Sucessos de vendas, com tiragens que chegavam a seiscentos mil exemplares por mês, ${ }^{15}$ foram e continuam sendo lidos por uma geração de mulheres brasileiras, das mais variadas classes sociais. Conforme Cunha, "as tiragens médias das séries em 2002 alcançavam, somadas, segundo a editora, 250 mil exemplares ao mês, número bem abaixo da época do boom de vendas das séries”, 16 mas ainda assim bastante significativo diante da realidade do mercado editorial brasileiro. Os romances sentimentais da Nova Cultural, até julho de 2011,

\footnotetext{
${ }^{15}$ SILVA. Leitoras indiscretas visitam as bancas, p. 95.

${ }^{16}$ RODRIGUEZ. Leitoras com coração: usos de leitura dos romances sentimentais de massa, p. 23.
} 
podiam ser comprados em edições semanais nas bancas de revistas ou adquiridos por assinatura; deste agosto de 2011, entretanto, apenas estão sendo vendidos no site da Editora, na forma de e-books ou por encomenda.

Neste ensaio, entretanto, a comparação entre a história de Romeu e Julieta será feita apenas em relação aos livros de M. Delly; e destes, selecionados os que foram publicados pela Biblioteca das Moças no Brasil.

\section{COMPARANDO OS ROMANCES DE BANCA COM ROMEU E JULIETA}

A comparação será feita da seguinte forma: cada parágrafo conterá, no seu início, um resumo destacado em itálico de uma parte do enredo de Romeu e Julieta; em seguida, serão apresentadas quais semelhanças e/ou diferenças a respeito do que foi escrito se encontram nos romances de M. Delly. Os parágrafos seguintes sempre continuarão o enredo no ponto em que foi interrompida a narrativa no anterior.

O enredo da história é iniciado com a apresentação da inimizade entre as famílias Capuleto e Montecchio, ambas nobres e com residência em Verona, Itália. Nos livros de M. Delly essa rixa de família nunca é tão forte ao ponto de uma família impor à outra a morte; entretanto, é bastante comum iniciar-se a história relatando que um membro masculino, por ter feito um casamento desigual, foi rejeitado pela família. Anos mais tarde, esse mesmo homem volta à família, tendo sua mulher falecido e estando ele mesmo com a saúde fortemente abalada, para implorar que cuidem de sua filhinha, que será órfã em breve. Assim, uma criança é colocada no seio de sua própria família, mas tomada pelo dever, não pela verdadeira caridade ou afeto. Desde esse momento, ela será considerada por todos como uma intrusa, uma estranha, e tratada de forma a sua posição social ser sempre inferior a dos demais parentes que vivem na casa. Normalmente o herdeiro do título nobiliárquico da família está na sua adolescência e, como os demais, sente verdadeira antipatia pela menina; o que vai mudar alguns anos depois, quando essa criança se fizer moça e, pela sua beleza, candura, moral elevada e encantos naturais, modificar sua situação perante a família devido ao amor que inspira no herdeiro.

Em seguida, conta-se que o velho senhor Capuleto ofereceu um grande banquete para muitas pessoas, mas nenhuma Montecchio fora convidado. É revelado que Romeu, filho do velho senhor Montecchio, era apaixonado por Rosalina, que iria à tal festa. Benvólio, um amigo de Romeu, persuadiu o jovem a comparecer ao evento disfarçado, a fim de perceber que sua amada não valia a pena, pois, na opinião do amigo, ela era muito feia, além de 
desprezar o amor de Romeu. Nos romances de Delly, não é comum bailes de máscaras, pois certamente isso seria considerado imoral demais para o casal de irmãos tão cristãos e rigorosos a respeito do lazer e da diversão. Entretanto, quase sempre ocorre de o protagonista ter outra paixão antes de amar a protagonista. Essa paixão, entretanto, como a de Romeu, é por uma mulher que não se iguala em beleza física e, especialmente, mental e moral à mocinha. São os sentidos do mocinho que estão apaixonados; essa paixão não é do coração, que será reservado apenas a uma mulher. Diferentemente de Rosalina, as paixões do mocinho nunca são indiferentes a ele, ao contrário, ele sempre é um homem que inspira amor no sexo oposto sem o menor esforço, o que lhe apraz o amor-próprio e o faz ir de flerte em flerte sem nunca ter um verdadeiro sentimento por nenhuma mulher.

Assim que Romeu viu Julieta dançando, foi arrebatado por sua beleza, sobre a qual teceu os mais poéticos elogios em voz alta. Em Delly, é mais comum que o amor seja descoberto aos poucos, uma vez que os protagonistas se conhecem desde a infância. Entretanto, é frequente acontecer que, durante a transição de menina a mulher experimentada pela mocinha, o mocinho esteja distante, estudando ou viajando. Quando ele retorna e a vê pela primeira vez como mulher, fica encantado e, a partir desse momento, se operam nele paulatinamente modificações relacionadas ao trato com a mocinha, a quem procurará agradar e tornar a vida mais feliz. Dessa forma, é possível dizer que também em Delly ocorre o amor à primeira vista se tomarmos como certo que é impossível que ele ocorra na infância e que é necessário o amadurecimento dos protagonistas.

Entretanto, em seu afã de elogiar a donzela, Romeu foi ouvido pelo primo dela, Tebaldo, que o reconheceu como um Montecchio penetra e, se não fosse impedido pelo anfitrião, teria partido para cima de Romeu. A partir desse momento, Tebaldo guardará para si o desejo de lutar contra Romeu. Em Delly, raramente ocorrem lutas em que o mocinho precisará provar a sua destreza com as armas. Embora alguns sejam oficiais do Exército, as lutas não são narradas. Normalmente, o mocinho é tido como tão superior aos demais homens quer fisicamente, quer intelectualmente, que nenhum se atreveria ir contra suas intenções.

Nesse momento, é revelado que o tio não permitiu que Tebaldo se rivalizasse com Romeu porque o rapaz até então fora comportado e era conhecido como um jovem virtuoso e comedido. Em Delly, embora o mocinho seja quase sempre bem visto pela sociedade, que praticamente o idolatra, também é conhecido por ser implacável em seus julgamentos, frio, austero, orgulhoso, impiedoso, impaciente e intolerante. Todos esses defeitos são atribuídos a uma má educação na infância, geralmente devido a uma mãe excessivamente permissiva, 
mundana, fraca aos caprichos do filho, a quem idolatra e por quem é pouco amada.

Após a dança, Romeu se dirigi até a sua nova paixão e, favorecido pelo seu disfarce, pega em sua mão e continua a elogiá-la, sempre usando de metáforas, que foram bem entendidas e se transformaram em um jogo de palavras entre os dois jovens. Em Delly, a questão dos elogios é sempre marcada pela compreensão dos autores, que entendem que o excesso de elogio prejudica a candura da mulher, tornando-a vaidosa, coquete e cheia de garridices. Portanto, a mocinha receberá muitos galanteios de outros homens, o que a deixará indiferente ou constrangida. O mocinho ficará encantado por sua beleza e caráter, mas os elogios serão lidos muito mais nos solilóquios de seu pensamento a respeito da amada do que nos diálogos que travará com ela.

A mãe da jovem dama a chamou para se retirar, e Romeu, então, descobriu que se tratava de Julieta, a herdeira dos Capuletos. Tinha entregado seu coração ao rival, mas, embora estivesse perturbado, não se dissuadiu de amá-la. Julieta, da mesma forma, descobriu que havia se apaixonado impetuosa e irrefletidamente por um Montecchio. Em Delly, raramente a protagonista terá uma mãe, o usual é que seja órfã. Outra diferença é ser comum que a mocinha e o mocinho, quando descobrem seus sentimentos, tentem anulá-los por causa da diferença de posição social ou pela inimizade que ainda se julgam ser objeto da parte do outro.

Soando meia-noite, Romeu e seus companheiros partiram, mas o jovem, incapaz de ficar longe da amada, escalou o muro do jardim nos fundos da casa de Julieta. Pouco tempo depois, ela apareceu na varanda da janela de seu quarto. Novamente, Romeu teceu os mais delicados e românticos elogios a sua beleza sem que fosse ouvido. Em Delly, sempre ocorre de o mocinho, ao ter seu coração arrebatado, deixar de lado aos antigos amigos e lazeres, tidos como mundanos demais, para ingressar em uma nova vida, mais retraída, de mais estudo, reflexão e fé cristã. Todavia, isso nunca lhe dá o direito de ir ao quarto da mocinha. M. Delly rigorosamente preza a castidade, por isso jamais os protagonistas se encontram no quarto enquanto são noivos, com exceção à situação de um deles se encontrar gravemente enfermo. Também o mocinho não tem o hábito de falar em voz alta (algo muito mais comum no gênero teatro), mas muitos de seus pensamentos são transcritos e o leitor pode acompanhar as suas impressões a respeito da amada e o amadurecimento do seu sentimento.

Julieta, sem saber da presença de Romeu, falou em voz alta de seu amor por ele. Romeu, ao escutá-la, não pode mais conter-se e revelou a sua presença. As faces de Julieta se ruborizaram, pois não era direito uma moça discreta confessar seus sentimentos dessa 
forma; o mais correto era fingir afetada indiferença quando mais se estivesse apaixonada, pois a dificuldade da obtenção aumenta o valor do objeto. Mas para Romeu nada dessas tradições importavam. Jamais em Delly a mocinha externa com palavras o seu sentimento antes de ele ser declarado pelo mocinho e isso é tido como valores de discrição e boa colocação femininos. Entretanto, é possível que o mocinho descubra o amor da amada em seus olhos e, como acontece com Julieta, pelas suas faces ruborizadas à sua presença.

Nesse diálogo apaixonado, Julieta foi chamada por sua ama, que dormia com ela, para se recolher. Então a moça disse a Romeu que, se seu amor fosse honrado e seu propósito o casamento, ela lhe enviaria um mensageiro no dia seguinte para marcar uma data para o enlace. Assim como Julieta, a mocinha de Delly sempre tem alguma senhora, boa ou má, que vela por ela, como criada ou amiga conselheira, impedindo que algum homem a comprometa. Mas, distintamente, nunca é a mulher quem toma a iniciativa de dizer quando o casamento vai ocorrer.

Quando finalmente se separaram, porém, o dia já vinha surgindo. Romeu decidiu ir procurar o frei Lourenço, seu amigo e quem até então lhe havia ouvido a respeito de Rosalina. O frei escutou sobre a nova paixão de Romeu e concluiu que o matrimônio entre os dois poderia ser um modo feliz de encerrar a longa rixa entre as famílias Capuleto e Montecchio, aceitando, portanto, a realizar o casamento. Assim como Romeu, os protagonistas de Delly frequentemente se aconselham com padres católicos, a única religião que toda mocinha tem e a que o mocinho virá a ter, por influência da amada, caso seja protestante no início do livro.

Um mensageiro entregou a Julieta um bilhete de Romeu para saber de suas intenções e não tardou em comparecer ao local estabelecido onde o frei Lourenço os uniu em matrimônio. Após a cerimônia, Julieta voltou às pressas para casa e esperou ansiosamente à noite, quando Romeu prometera ir encontrá-la. Os casamentos dos protagonistas dos romances de Delly nunca são feitos em segredo, uma vez que o mocinho é independente e senhor de seu título e fortuna. É comum que a família não aprove o enlace, mas todos têm que se conformar. Entretanto, o matrimônio em segredo é comum de ocorrer entre outros familiares, especialmente entre os pais da mocinha, o que é descoberto no final do livro e revela uma herança inesperada ou um título de nobreza até então inimaginável, o que permite o matrimônio entre os protagonistas, agora de mesma posição social.

Naquela mesma manhã, Romeu e seus amigos caminhavam pelas ruas quando encontraram um grupo de Capuletos liderados por Tebaldo. Houve troca de acusações entre 
Tebaldo e Mercúcio, amigo de Romeu, e a luta entre os dois se iniciou, terminando com a morte de Mercúcio. Romeu, que até então contivera sua raiva, pelo fato de Tebaldo ser da família de sua esposa, não pôde se conter mais e atacou Tebaldo, lutando até a morte do rapaz. Não há, em Delly, lutas como essa. O mocinho apenas inflige a morte quando é oficial do Exército francês ou russo aos alemães durante alguma guerra (geralmente não se explica qual é). Nos romances, influenciados pelos horrores da Segunda Guerra Mundial, os irmãos franceses Frédéric Henri e Jeanne Marie fizeram dos alemães sempre o inimigo, apresentados como desonestos, desleais, desonrosos.

Várias pessoas foram às ruas ver o que estava acontecendo, inclusive os senhores Capuleto e Montécchio e o príncipe. As testemunhas contaram o ocorrido, e a família de Tebaldo exigia que o príncipe fizesse valer a justiça, punindo Romeu. O príncipe, então, sentenciou que Romeu deveria ser banido de Verona. Novamente, esse tipo de conflito não ocorre em Delly.

Julieta, ao saber dos fatos, irrompeu, inicialmente numa fúria contra Romeu; mas logo o amor tomou controle e ela pôde aceitar e compreender a situação. Romeu buscou refúgio com frei Lourenço, que teve de usar toda a sua sabedoria para consolar o rapaz, que queria buscar a morte para não se ver separado de Julieta. Toda essa situação é bastante frequente nos romances. Muitas vezes a mocinha perde a confiança no amado após ouvir de uma rival algo que mancha o caráter dele e, consequentemente, o seu amor por ele. Também o mocinho, mais fraco moralmente que a mocinha até quase o final do livro, quando se igualam moralmente por causa de sua conversão ao catolicismo, pensa na morte nas situações em que julga perder a amada ou o filho. E é a fé cristã, levada até ele pela própria amada, por um padre ou por suas orações na igreja, que lhe incutem forças para continuar vivendo.

Todo o restante do livro, quando Romeu é banido, Julieta é obrigada a se casar com Páris, o frei a aconselha a tomar o veneno, o engano a respeito da morte da amada e a morte de Romeu seguidos pela morte de Julieta não encontra ressonâncias nos romances de Delly. Talvez a única semelhança seja a presença do veneno, que nunca é tomado propositadamente, mas costuma ser ministrado por uma rival que quer a morte da mocinha.

\section{CONCLUSÃO}

Após a análise comparativa entre a história de Romeu e Julieta e os romances de M. Delly, podemos concluir que o casal de irmãos não se utilizou do enredo ou da caracterização dos personagens da história de amor mais conhecida no mundo para criar os seus livros. Há 
algumas semelhanças entre a história do bardo e as de Delly, porém estas se devem à proximidade do tema, da época da narrativa e dos costumes e não a alguma influência. Resta saber - e isso fica como sugestão para um próximo ensaio - se as coleções atuais dos livros de banca encontram alguma ressonância com a obra de Shakespeare.

\begin{abstract}
Romeo and Juliet is the most popular love story in the world. Has the romance novel received any influence of this work? This paper attempts to answer this question by means of a comparison between the prose version of the play, written by the Lamb brother and sister in 1807, with M. Delly novels, sold at Brazilian newsstands in the decades of 1930-1960.
\end{abstract}

\title{
KEYWORDS
}

Romeo and Juliet, M. Delly, romance novel

\section{REFERÊNCIAS}

CARVALHO, Cleiry de Oliveira. Romance de mocinha \& romance de mocinho: a literatura narrativa de massa por um convívio dos contrários. Dissertação (Mestrado em Letras). Centro de Ciências Humanas, Letras e Artes, Universidade Estadual de Maringá. Maringá, 2007.

CUNHA, M. T. S. Armadilhas da sedução: os romances de M. Delly. Belo Horizonte: Autêntica, 1999.

HAWKERS, Terence. Introduction. In: Alternative Shakespeare. London/New York: Routledge, 1996. v. 2. p. 1-16.

HELIODORA, Barbara. Falando de Shakespeare. Lisboa: Edições Cosmos, 1996.

LAMB, Charles; LAMB, Mary. Romeu e Julieta. In: . Histórias de Shakespeare. São Paulo: Ática, 2005. v. 1. p. 7-33.

MARJORIE, Garber. Introduction. In: . Shakespeare and modern culture. New York: Pantheon, 2008. p. xiii-xxxv.

MARTINS, Márcia A. P. Visões e identidades brasileiras de Shakespeare. São Paulo: Perspectiva, 1997.

PRADO, Rosane. Um ideal de mulher: estudo dos romances de M. Delly. In: FRANCHETTO, Bruna et al. (Org.). Perspectivas antropológicas da mulher. Rio de Janeiro: Zahar Editores, 1981. v. 2. p. 71-112.

RODRIGUEZ, Simone Meirelles. Leitoras com coração: usos de leitura dos romances sentimentais de massa. Revista Letras, Editora UFPR, Curitiba n. 65, p. 23-37. jan./abr. 2005. 
SILVA, Paulo Sérgio. Leitoras indiscretas visitam as bancas. São Paulo, 1994. 210f. Dissertação (Mestrado em Ciências da Comunicação), Departamento de Comunicações e Artes, Universidade de São Paulo. 